\title{
Matsuo Memorial Issue: Magmatic Volatiles and Volcanic Discharges Preface
}

\author{
Minoru KuSAKabe ${ }^{1}$ and Hiroshi Shinohara ${ }^{2}$ \\ Institute for Study of the Earth's Interior, Okayama University, \\ Misasa, Tottori-ken $682-01^{1}$ and \\ Minerals Resources Division, Geological Survey of Japan, \\ 1-1-3 Higashi, Tsukuba, Ibaraki 305, Japan ${ }^{2}$
}

This special issue of the Geochemical Journal has been organized by the Geochemical Society of Japan in memory of the late Professor Sadao Matsuo, who died of a sudden heart attack on 8 May 1992 (obituary in Geochem. J. 26, 179-180, 1992). This volume is a collection of 16 papers contributed by Professor Matsuo's former students, colleagues and friends from all over the world, covering a wide spectrum of his interests from the chemistry of volcanic gases to the evolution of the atmosphere and hydrosphere.

Professor Matsuo became interested in magmatic volatiles when he started his Ph.D. study in 1953 on the volcanic gas discharges of Showa-Shinzan, a new and still very hot dacite dome which formed during 1943-45. He applied chemical thermodynamics to interpret the gas compositions and estimated the temperature at which the fumarolic gases were in equilibrium with the magma. He treated published Hawaiian gas data in a similar fashion. His approach was fresh and unique at that time, and provided a strong influence for later studies of volcanic gases. He also conducted pioneering studies on the stable isotopic compositions of hydrogen, oxygen and carbon in volcanic gases, geothermal waters, mantle minerals and so on. The origin of volcanic waters was one of his main interests, and was examined in relation to hydrous minerals, magma degassing and mixing with meteoric water. He was enthusiastic in studying magmatic processes not only on the basis of chemical and isotopic signatures, but also through inert gas and trace element characteristics. In addition, he was also keen to develope techniques for the in situ analysis of volcanic gases and for extraction of volatiles from volcanic rocks and minerals. He always tried to integrate all available information into a model for the origin of volcanic gas and the evolution of Earth's atmosphere. The ultimate goal of his studies was to improve his own view of the origin and evolution of Earth's oceans and atmosphere.

Mantle degassing has obviously played an important role in the evolution of the atmosphere and hydrosphere. In contrast to highly reactive gases such as $\mathrm{H}_{2} \mathrm{O}$ and $\mathrm{CO}_{2}$, which constitute the major portion of magmatic volatiles, noble gases provide more direct information on mantle degassing through volcanism because of their chemically inert nature. For this reason, the abundance patterns and isotopic variations of noble gases have been widely applied to problems of mantle degassing, magma degassing and crustal contamination of magmas. In this volume, a model for the origin of terrestrial noble gases is proposed by Ozima and Zahnle on the basis of recent, high quality experimental data. The isotopic compositions of the terrestrial noble gases are the result of a multi-stage evolution from gravitational capture of solar-type noble gases by planetesimals, fractionation during hydrodynamic escape of hydrogen, and degassing during the magma ocean stage. Kaneoka stresses importance of the isotopic ratios and abundance patterns of noble gases in 
characterizing the magma sources and magmatic processes. He discussed how the noble gas abundance patterns of igneous rock components are affected by various magmatic processes, i.e., partial melting, fractional crystallization, transportation and degassing. A mathematical model of noble gas elemental fractionation during crystallization and degassing is presented by Spasennykh and Tolstikhin; their model explains the relative excess of $\mathrm{Ne}$ and $\mathrm{Xe}$ over $\mathrm{Ar}$ found in MORB glasses. The noble gas composition of volcanic glasses, phenocrysts or xenoliths can constrain the origin of magma, the geochemical structure of the mantle, and the model of the atmospheric evolution. New noble gas isotopic data are presented by Marty et al. for basaltic glass and olivine phenocrysts from Afar, Republic of Djibouti. The high ${ }^{3} \mathrm{He} /{ }^{4} \mathrm{He}$ ratio (up to $15 \mathrm{Ra}$ ) for these samples indicates the presence of ${ }^{3} \mathrm{He}$-rich hot spot beneath Afar. Nagao and Takahashi measured the noble gas isotopic compositions of xenoliths from wedge mantle and lower crust beneath the Japanese island arc. The isotopic compositions of gases in the wedge mantle are similar to MORB-type gases. However, gases in the lower crust have lower ${ }^{3} \mathrm{He} /{ }^{4} \mathrm{He}$ ratios than MORB-type gases and the ratios are identical to those found in samples of high temperature volcanic gas in Japan. This correlation provides an important constraint on the origin of noble gases in arc volcanic discharges, suggesting they are likely derived from the lower crust. The stable isotopic composition of carbon can also constrain the origin of the gases, since it has a characteristic range of variation for a given material. Cornides emphasizes that mantle $\mathrm{CO}_{2}$ is discharging to the surface in tectonically quiet regions such as the Carpathian basin of central Europe, based on a large number of $\delta^{13} \mathrm{C}$ measurements of $\mathrm{CO}_{2}$-rich spring waters there.

Variation in the composition of volcanic gas over space and time provides important information on the evolution of a volcanic system. Island arc volcanic gases have a maximum ${ }^{3} \mathrm{He} /{ }^{4} \mathrm{He}$ ratio of $10 \times 10^{-6}$, and lower ratios result from mixing with gases from the at- mosphere and/or crust. Kita et al. reported the ${ }^{3} \mathrm{He} /{ }^{4} \mathrm{He}$ and ${ }^{4} \mathrm{He} /{ }^{20} \mathrm{Ne}$ ratios of volcanic gases collected from currently erupting Unzen volcano, and concluded that mixing of crustal ${ }^{4} \mathrm{He}$ lowers the original, high ${ }^{3} \mathrm{He} /{ }^{4} \mathrm{He}$ ratio of the magmatic gas. An example of temporal variation in the isotopic composition of water in volcanic gas was shown for Izu-Oshima volcano. Kazahaya et al. argue that this variation is due to a change in the proportion of magmatic water, meteoric water and seawater, responding to subsidence of the magma after eruption. Near-surface differentiation processes can result in volcanic gas discharges with a highly variable gas composition despite fumaroles being close to one another. Shinohara et al. identify these nearsurface differentiation processes and estimate a representative volcanic gas composition discharging from Satsuma Iwojima, a volcanic island south of Kyushu, Japan. The acidic hot spring waters of the island are mixtures of volcanic gas and groundwater, based on the chemical and isotopic compositions of the volcanic gases, hot spring waters and meteoric waters. The chemical composition and carbon isotopes of $\mathrm{CH}_{4}$ and $\mathrm{CO}_{2}$ measured by Ono et al. for hydrothermal gases in Japan indicate that the $\mathrm{CO}_{2}$ largely originates from subduction-related magmatism. Martini applied a factor analysis to the water and gas analyses from Vulcano over the period of 1977 to 1991, and concluded that the variation in temperature and chemical composition of the volcanic gases results from a fluctuation in the proportion of different components; the deep seated magma (fire) and the near-surface aqueous environment (water).

The chemical compositions of volcanic gas samples may have been modified through contamination and other problems in sampling techniques. A data analysis on the basis of chemical equilibrium is now a standard method to assess the reliability of volcanic gas samples, and is widely applied in modeling the processes occurring in the gas vent. Gerlach presents an example of the thermodynamic restoration of Kilauea gas compositions obtained by modern collection and analytical methods. These calculations 
demonstrate that the ten volcanic gas samples are in equilibrium with the magma at its measured temperature, about $100^{\circ} \mathrm{C}$ higher than those measured at the sampling point. Thermodynamic modeling of the volcanic gas now includes not only major components such as $\mathrm{H}, \mathrm{O}$, $\mathrm{C}, \mathrm{S}$ and halogens, but also minor metallic components. A series of new methods for the complete collection of volcanic gas is summarized by Le Guern et al. Using computer modeling, they are also able to reproduce the sequence of sublimates deposited in a silica sampling tube as a result of temperature decrease. With this modeling, a new concept is proposed for monitoring the emission temperature of the volcanic gases from the chemical composition of a plume. The texture of sublimates collected by the silica tube method also provides information on the growth process of the sublimates. Symonds concluded from SEM observation of sublimates collected in a silica tube that they are in equilibrium with the gas phase at the beginning of growth but fail to maintain equilibrium because of the high velocity of the gas passing through the tube.

The concentrations of some trace elements in volcanic gases are more sensitive to changes in temperature and pressure than those of major components, and therefore trace elements are useful for monitoring volcanic activity. Mambo and Yoshida measured the As content of volcanic gases, sulfur sublimates and altered rocks from many Japanese volcanoes, and found that the As content of volcanic gas is dependent on the fumarolic temperature. Gas flux from a volcano also provides information on its activity. The correlation spectrometer (COSPEC) measures the $\mathrm{SO}_{2}$ flux, and is now a standard geochemical tool for volcano monitoring. However, species other than $\mathrm{SO}_{2}$ cannot be measured by COSPEC. An infrared spectral radiometer, which can theoretically measure $\mathrm{HCl}$ as well as $\mathrm{SO}_{2}$, has been developed by Notsu et al. for remote monitoring of volcanic gases. They succeeded in detecting $\mathrm{SO}_{2}$ in the plume of Mt. Asama volcano from a ground station $4 \mathrm{~km}$ away from the crater.

The authors of the papers in this special issue have, to varying degree, been affected by Professor Matsuo's enthusiasm in the study of volcanic gases, magmatic volatiles and mantle degassing. We are pleased to find that the seeds he sowed over this wide field have grown and come to fruition as the many papers published in this volume. We thank Y. Matsuhisa and T. Ohsumi, Executive and Managing Editors, respectively, of the Geochemical Journal, for their support in editing the manuscript in this issue. We also thank the following journal referees, whose constructive comments improved the quality of the papers published here. They include T. Abiko, B. Andres, A. Bernard, R. Cioni, F. D'Amore, T. Gerlach, H. Hiyagon, M. Honda, J. Hulston, I. Kaneoka, K. Kazahaya, I. Kita, Y. Kiyosu, R. Krouse, Y. Kuroda, F. Le Guern, B. Marty, O. Matsubaya, Y. Mizutani, K. Nagao, T. Ohba, W. Rose, Y. Sano, T. Staudacher, R. Symonds, N. Takaoka, B. Taylor, D. Tedesco, I. Tolstikhin, A. Ueda, J. Varekamp, H. Wakita and J. Welhan. 